\title{
Nanocrystalline strain glass TiNiPt and its superelastic behavior
}

\author{
Daqiang Jiang ${ }^{\mathrm{a}, *}$, Jiale $\mathrm{An}^{\mathrm{a}}$, Yinong Liu ${ }^{\mathrm{b}, *}$, Zhiyuan Ma ${ }^{\mathrm{a}}$, Fangfeng Liu ${ }^{\mathrm{a}}$, Hong Yang ${ }^{\mathrm{b}}$, \\ Xiaobing Ren ${ }^{\mathrm{c}}$, Kaiyuan $\mathrm{Yu}^{\mathrm{a}}$, Junsong Zhang ${ }^{\mathrm{b}}$, Xiaohua Jiang ${ }^{\mathrm{a}}$, Yang Ren ${ }^{\mathrm{d}}$, Lishan Cui ${ }^{\mathrm{a}, \mathrm{e}, *}$ \\ a State Key Laboratory of Heavy Oil Processing and Department of Materials Science and \\ Engineering, China University of Petroleum, Beijing 102249, China. \\ b Department of Mechanical Engineering, The University of Western Australia, Perth, WA 6009, \\ Australia \\ c Frontier Institute of Science and Technology, and State Key Laboratory for Mechanical \\ Behaviour of Materials, Xi' an Jiaotong University, Xi'an 710049, China \\ d X-ray Science Division, Argonne National Laboratory, Argonne, IL 60439, USA \\ e Beijing Key Laboratory of Failure, Corrosion, and Protection of Oil/Gas Facilities, China \\ University of Petroleum Beijing, Beijing 102249, China \\ *Corresponding author: Tel.: +86 10 89739341; fax: +86 10 89731959; \\ E-mail: dq80jiang@126.com, yinong.liu@uwa.edu.au, lscui@cup.edu.cn
}

\begin{abstract}
TiNi-based shape memory alloys are known to exhibit a strain glass state under certain conditions, generally in the presence of high density defects such as excess solute atoms or alloying elements, dislocations and nano precipitates. In this paper, we report a strain glass transition in a nanocrystalline Ti50Ni35 $\mathrm{Pt}_{15}$ alloy. The nanocrystalline strain glass state is achieved by a combined effect of high density grain boundaries and high concentration doping of $\mathrm{Pt}$ atoms in the $\mathrm{B} 2$ matrix. The nanocrystalline $\mathrm{Ti}_{50} \mathrm{Ni}_{35} \mathrm{Pt}_{15}$ strain glass alloy showed a large near-complete progressive superelasticity with a recovery strain of about $6 \%$ and a low apparent Young's modulus of about $30 \mathrm{GPa}$ in a wide temperature range of over $200{ }^{\circ} \mathrm{C}$. Insitu synchrotron XRD measurement showed that the strain glass B2 (B2(SG)) phase experienced $\mathrm{B} 2$ (SG) $\rightarrow \mathrm{R} \rightarrow \mathrm{B} 19$ transformation upon loading and B19 $\rightarrow \mathrm{B} 2$ (SG) upon unloading. The findings of this study provide insight for the development of nanocrystalline strain glass shape memory alloys.
\end{abstract}

Keywords: TiNiPt; Strain glass; Martensitic phase transformation; Nanocrystalline; Shape memory alloy; Superelasticity

\section{Introduction}

"Strain glass" describes a special state of a crystalline metal matrix composed of a vast population and high density of nano-domains of lattice distortions in random orientations [1]. Such state occurs in alloys that generally exhibit martensitic transformations but when the transformations are suppressed by high densities of structural defects. These defects in high 
densities create very small inter-defect distances in the order of several nanometers, which break down the long-range order of the crystalline matrix and severely impede mechanically the crystallographic lattice distortions of the otherwise thermodynamically favored martensitic transformation. This results in miniscule local lattice distortion strains, often beyond the detection of conventional lattice diffraction techniques, within a massive population of local nano domains of random orientations, thus the "strain glass" state.

The strain glass state was first reported in some Ni-rich TiNi shape memory alloys (SMAs) [2], containing high densities of third element atoms [3-8], dislocations [9], and nano-precipitates $[10,11]$. Four main experimental characteristics are often used to verify the occurrence of strain glass state [2], including an invariance of average structure of the parent phase (B2 for TiNi) with decreasing temperature, the frequency-dependence of ac mechanical susceptibility obeying Vogel-Fulcher relation, the breakdown of ergodicity or the existence of history dependence of physical properties (strain), and the presence of nanodomains of local lattice strains.

This strain glass state of martensitic transforming alloys provides them a unique mechanism for some novel properties that are absent in conventional alloys of more ordered and relaxed lattices, such as the Invar effect, Elinvar effect, large magnetostriction, small hysteresis, high damping, low modulus, and transformation pseudoelasticity over extraordinary wide temperature ranges [2-7, 12-16].

It has been reported recently that the thermally induced B2-R and B2-B19' martensitic transformations can be suppressed in nanocrystalline TiNi-based alloys (containing high density of grain boundaries) formed by crystallization from an amorphous state through low temperature annealing [17]. TEM studies reveal that the B19' martensite is fully suppressed in grains smaller than $60 \mathrm{~nm}$ and the R-phase is suppressed when the grain size is further reduced to $15 \mathrm{~nm}$ even upon cooling to the cryogenic temperature [18]. The suppression of martensitic transformations in these alloys fulfills a prerequisite for achieving strain glass state $[4,6,7$, 13], though grain size reduction has generally not been considered an effective way to form strain glasses. This is largely due to the difficulty in achieving grain sizes small enough to reach the critical defect density (inter defect spacing) for forming strain glasses and to have a high uniformity of these very small nano grains without abnormal growth. This often results in the local occurrence of B2-R transformation in the larger grains in these nanocrystalline TiNi alloys $[18,19]$.

Ren et al. [20] studied the effect of Pd (a larger atom than both $\mathrm{Ti}$ and $\mathrm{Ni}$ ) doping in causing the strain glass state in $\mathrm{Ti}_{50} \mathrm{Ni}_{50-\mathrm{x}} \mathrm{Pd}_{\mathrm{x}}$. They found that $\mathrm{Pd}$ doping alone is insufficient to disrupt the long-range order of the $\mathrm{B} 2$ phase in $\mathrm{Ti}_{50} \mathrm{Ni}_{50-\mathrm{x}} \mathrm{Pd}_{\mathrm{x}}$, but a slight increase of $\mathrm{Ni}$ content by 1 at. \% changed $\mathrm{Ti}_{49} \mathrm{Ni}_{51-\mathrm{x}} \mathrm{Pd}_{\mathrm{x}}$ into a strain glass state. This implies that a strain glass state is easier to achieve by co-doping of multiple species, demonstrating the synergy between the different contributors. Considering the above, we may expect that doping of TiNi by a third element may help to increase the critical grains size, or increase the grain size tolerance, for achieving the strain glass state in nanocrystalline TiNiX alloys. This will alleviate the materials processing 
difficulty in achieving uniform nanocrystalline microstructures. This study applied this concept and investigated the synergy between nanocrystallization and Pt doping on inducing the strain glass state in a $\mathrm{Ti}_{50} \mathrm{Ni}_{35} \mathrm{Pt}_{15} \mathrm{SMA}$ and its thermomechanical behaviour.

\section{Experimental procedure}

A $\mathrm{Ti}_{50} \mathrm{Ni}_{35} \mathrm{Pt}_{15}$ (at. \%) ingot about $100 \mathrm{~g}$ in mass was prepared by vacuum arc melting from high purity Ti (99.8 wt. \%), Ni (99.9 wt. \%) and Pt (99.95 wt. \%) in an Ar atmosphere. The ingot was homogenized at $1050{ }^{\circ} \mathrm{C}$ for $12 \mathrm{~h}$ in a vacuum furnace and then hot-rolled into a plate of $1.0 \mathrm{~mm}$ in thickness. Thin strips of $1.0 \mathrm{~mm} \times 1.0 \mathrm{~mm}$ in cross section were cut from the plate along the rolling direction by means of electrical discharge wire cutting and then subjected to cold wire drawing into thin wires of $0.23 \mathrm{~mm}$ in diameter in multiple steps with process annealing at $750{ }^{\circ} \mathrm{C}$. The areal reduction of the last cold drawing was $79 \%$.

The cold-drawn wire was in amorphous state, as confirmed by XRD measurement [21, 22]. The crystallization behavior of the cold-drawn wire was measured using a TA Q20 differential scanning calorimeter (DSC) with a heating/cooling rate of $10^{\circ} \mathrm{C} / \mathrm{min}$. The crystallization peak temperature was $480^{\circ} \mathrm{C}$. Consequently, all the nanocrystalline samples were annealed at $480{ }^{\circ} \mathrm{C}$ for $10 \mathrm{~min}$. Dynamic mechanical analysis (DMA) was carried out in tensile mode using a TA Q800 instrument with a cooling rate of $2{ }^{\circ} \mathrm{C} / \mathrm{min}$ to characterize the strain glass transition with a constant displacement amplitude of $10 \mu \mathrm{m}$ and in five frequencies $(0.2,1,5,10$ and $20 \mathrm{~Hz})$. The "zero force cooling" (ZFC) and "forced cooling" (FC) measurements were performed sequentially in two temperature cycles with a cooling rate of $5^{\circ} \mathrm{C} / \mathrm{min}$ by using a TA Q800 DMA unit. In this process, the sample was first cooled to $-150{ }^{\circ} \mathrm{C}$ under zero stress. A load of $50 \mathrm{MPa}$ was applied at this temperature and then the sample was heated to $300{ }^{\circ} \mathrm{C}$ under this stress. Then, the sample was cooled and heated with the same stress through the temperature cycle the second time. Electrical resistivity of the sample was measured by the four-probe method with a cooling/heating rate of $10^{\circ} \mathrm{C} / \mathrm{min}$ in vacuum.

The microstructure of the alloy wire was analyzed by means of transmission electron microscopy using a Tecnai F20 microscope. The microstructure was characterized using the hollow-cone dark field (HCDF) imaging method, which is suitable to form high image contrast for nanocrystalline microstructure [23]. In-situ synchrotron high energy X-ray diffraction (HEXRD) measurements were conducted at the 11-ID-C beamline of the Advanced Photon Source at Argonne National Laboratory, USA. HEXRD was used to investigate the structure and lattice strain evolutions of the alloy during tensile deformation. The X-ray had a beam size of $0.4 \mathrm{~mm} \times 0.4 \mathrm{~mm}$ and a wavelength of $0.0108 \mathrm{~nm}$. The diffraction was generated in a transmission geometry. Tensile testing was carried out using a WDT-II tensile testing machine with a strain rate of $1 \times 10^{-3} \mathrm{~s}^{-1}$.

\section{Results}

\subsection{Evidence of nanocrystalline strain glass state}

Fig. 1 shows a TEM analysis of the microstructure of the $\mathrm{Ti}_{50} \mathrm{Ni}_{35} \mathrm{Pt}_{15}$ alloy wire after annealing at $480{ }^{\circ} \mathrm{C}$ for $10 \mathrm{~min}$. Fig. 1a is a hollow-cone dark field (HCDF) micrograph of the sample generated using the (110)в2 diffraction ring. The inset is a selected area electron diffraction 
pattern. The sample was fully crystalline. Fig. 1b shows the grain size distribution of 1000 grains in the sample. The average grain size is $\sim 13 \mathrm{~nm}$.
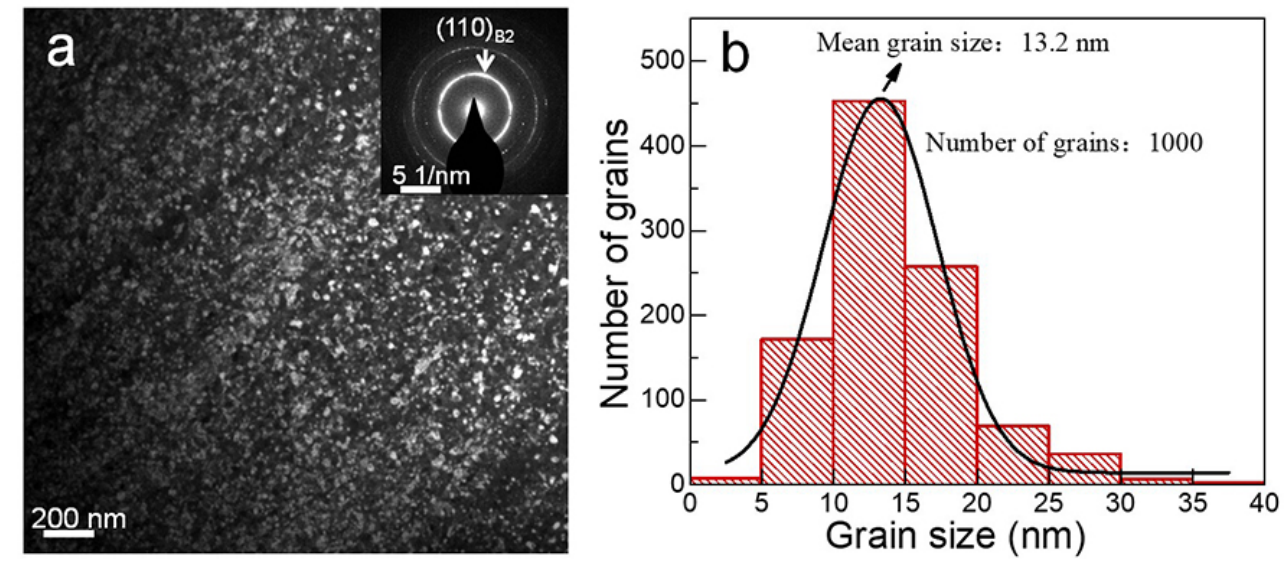

Fig. 1. Microstructure of the nanocrystalline $\mathrm{Ti}_{50} \mathrm{Ni}_{35} \mathrm{Pt}_{15}$ alloy wire after annealing at $480{ }^{\circ} \mathrm{C}$ for $10 \mathrm{~min}$. (a) A hollow-cone dark field image, revealing the nanocrystallinity of the sample. (b) Grain size distribution as determined from the HCDF image.

Fig. 2 shows the transformation behavior and structure evolution of the nanocrystalline $\mathrm{Ti}_{50} \mathrm{Ni}_{35} \mathrm{Pt}_{15}$ sample. Fig. 2a shows the transformation behaviors of the nanocrystalline $\mathrm{Ti}_{50} \mathrm{Ni}_{35} \mathrm{Pt}_{15}$ alloy and a coarse-grained $\mathrm{Ti}_{50} \mathrm{Ni}_{35} \mathrm{Pt}_{15}$ sample prepared by annealing at $700{ }^{\circ} \mathrm{C}$ for $10 \mathrm{~min}$. The nanocrystalline $\mathrm{Ti}_{50} \mathrm{Ni}_{35} \mathrm{Pt}_{15}$ wire showed no transformation within the temperature range of $40-220^{\circ} \mathrm{C}$. This is different from previously reported observations, in which nanocrystalline TiNi alloys of similar grain sizes exhibited clear B2-R transformation at about $50{ }^{\circ} \mathrm{C}[18,19]$. In comparison, the coarse-grained sample showed a clear reversible B2-B19 martensitic transformation at around $180{ }^{\circ} \mathrm{C}$ during heating and cooling.
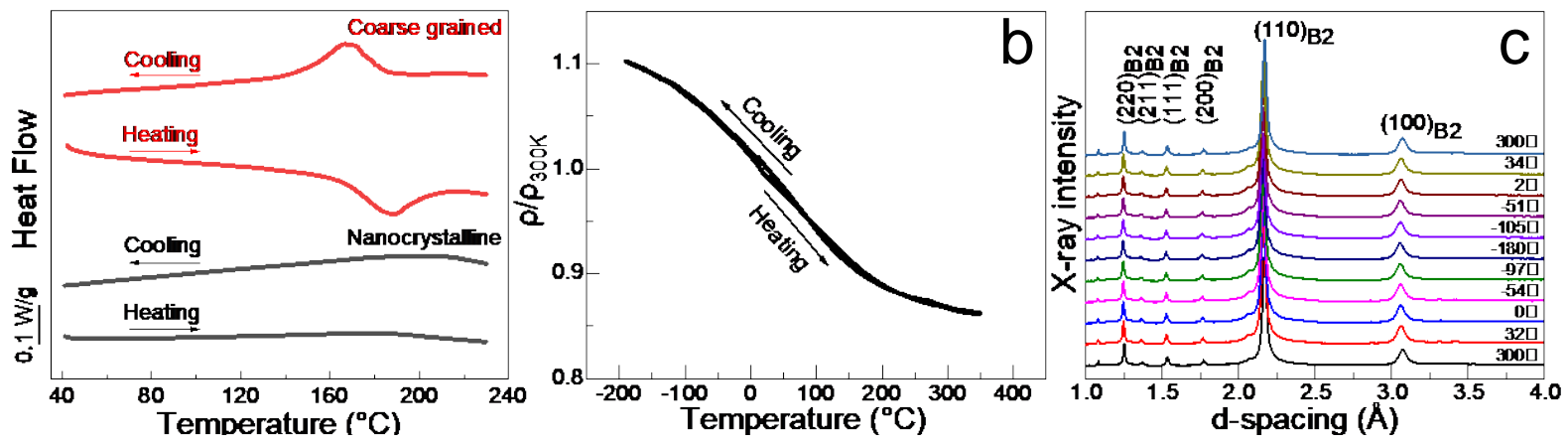

Fig. 2. The transformation behavior and structure evolution of the nanocrystalline $\mathrm{Ti}_{50} \mathrm{Ni}_{35} \mathrm{Pt}_{15}$ sample (a) DSC curves of the nanocrystalline Ti50Ni35 $\mathrm{Pt}_{15}$ sample and a coarse-grained $\mathrm{Ti}_{50} \mathrm{Ni}_{35} \mathrm{Pt}_{15}$ sample annealed at $700{ }^{\circ} \mathrm{C}$ for $10 \mathrm{~min}$. (b) Normalized (at $300 \mathrm{~K}$ ) electrical resistivity - temperature curve of the nanocrystalline $\mathrm{Ti}_{50} \mathrm{Ni}_{35} \mathrm{Pt}_{15}$ alloy. (c) XRD patterns of the nanocrystalline $\mathrm{Ti}_{50} \mathrm{Ni}_{35} \mathrm{Pt}_{15}$ alloy at different temperatures.

Fig. 2b shows a normalized electrical resistivity (ER) curve of the nanocrystalline $\mathrm{Ti}_{50} \mathrm{Ni}_{35} \mathrm{Pt}_{15}$ sample during heating and cooling. It can be seen that the ER started to increase at $350{ }^{\circ} \mathrm{C}$ upon 
cooling and continued to $-180^{\circ} \mathrm{C}$. Upon heating the sample showed the reverse process without a thermal hysteresis. Such abnormal increase of ER with lowering temperature in TiNi has been attributed to the formation and growth of "R-like" nanodomains within the B2 matrix [24]. The onset temperature for the abnormal increase of ER, denoted as $\mathrm{T}_{\text {nd }}$ [8], indicates that the nanodomains begin to form as high as $350{ }^{\circ} \mathrm{C}$ in the nanocrystalline $\mathrm{Ti}_{50} \mathrm{Ni}_{35} \mathrm{Pt}_{15}$ alloy. This is much higher than the previously reported $\mathrm{T}_{\text {nd }}$ of $80^{\circ} \mathrm{C}$ in strain glass TiNi [25] and $100{ }^{\circ} \mathrm{C}$ in strain glass TiPdFe [11].

Fig. 2c shows an in-situ high-energy synchrotron XRD measurement of the nanocrystalline $\mathrm{Ti}_{50} \mathrm{Ni}_{35} \mathrm{Pt}_{15}$ sample at different temperatures. It is seen that the sample remained in $\mathrm{B} 2$ structure over the entire temperature range from $300{ }^{\circ} \mathrm{C}$ to $-180{ }^{\circ} \mathrm{C}$. This is consistent with the characteristic that strain glass TiNi maintains its B2 structure [13].

Fig. 3 shows a dynamic mechanical analysis of the nanocrystalline $\mathrm{Ti}_{50} \mathrm{Ni}_{35} \mathrm{Pt}_{15}$ sample. Fig. 3a plots the storage modulus curves of the sample at different frequencies. It is seen that the storage modulus decreased with decreasing temperature from $90{ }^{\circ} \mathrm{C}$ and reached a minimum at about $50-60^{\circ} \mathrm{C}$, and then started to increase with decreasing temperature. The temperature of the lowest storage modulus is identified as the $\mathrm{T}_{\mathrm{g}}$ temperature of the alloy at which the matrix transformed from an unfrozen strain glass state into a frozen strain glass state on cooling [3]. The inset in Fig. 3a shows the Vogel-Fulcher fitting curve of $\mathrm{T}_{\mathrm{g}}$. It is seen that $\mathrm{T}_{\mathrm{g}}$ increased with increasing the frequency $\omega$, and the dependence obeys a Vogel-Fulcher relationship [26] $\omega=\omega_{0} \cdot \exp \left[-\mathrm{E}_{\mathrm{a}} / \mathrm{k}_{\mathrm{B}}\left(\mathrm{T}_{\mathrm{g}}(\omega)-\mathrm{T}_{0}\right)\right]$, where $\omega_{0}, \mathrm{E}_{\mathrm{a}}, \mathrm{k}_{\mathrm{B}}$ and $\mathrm{T}_{0}$ are the frequency pre-factor, activation energy, Boltzmann constant and ideal freezing temperature of the strain glass transition, respectively. The ideal freezing temperature $\mathrm{T}_{0}$ is determined to be $\sim 49{ }^{\circ} \mathrm{C}$ from the fitting curve. Another major feature of strain glass transition is the nonergodicity, which is demonstrated by measuring the historical dependence of strain under a small external stress.

Fig. 3b shows strain-temperature measurements of a nanocrystalline $\mathrm{Ti}_{50} \mathrm{Ni}_{35} \mathrm{Pt}_{15}$ sample upon heating over two measurement cycles. In the first measurement cycle the sample was cooled to $-150{ }^{\circ} \mathrm{C}$ under zero applied force (denoted zero-field cooling, or ZFC) to produce a randomly oriented frozen strain nanodomain structure. Then a tensile stress of $50 \mathrm{MPa}$ was applied and the sample was heated to $300{ }^{\circ} \mathrm{C}$ under this stress, presented as the ZFC curve in the figure. In the second measurement cycle, the sample was cooled to $-150{ }^{\circ} \mathrm{C}$ under the $50 \mathrm{MPa}$ tensile stress to form an oriented frozen strain nanodomain structure, denoted the field cooling, or FC. The sample was then heated to $300^{\circ} \mathrm{C}$ again under the same stress, presented as the FC curve in the figure. For each curve, the effect of thermal dilation of the sample has been removed by subtracting the strain-temperature curve measured upon the first cooling under zero stress. The ZFC sample showed an initial increase of strain from $-60{ }^{\circ} \mathrm{C}$ to $20^{\circ} \mathrm{C}$. This is attributed to a stress-assisted strain reorientation of the randomly oriented nanodomains formed under the ZFC condition, apparently due to thermal relaxation (unfreezing) upon heating. This caused a large deviation between the two curves at below $\mathrm{T}_{\mathrm{g}}$, revealing a strong nonergodicity of the straining process. This is similar to the ZFC/FC curves of spin glasses and ferroelectric relaxors $[27,28]$, and has been used as evidence of the freezing of a strain glass phase $[3,13]$. 

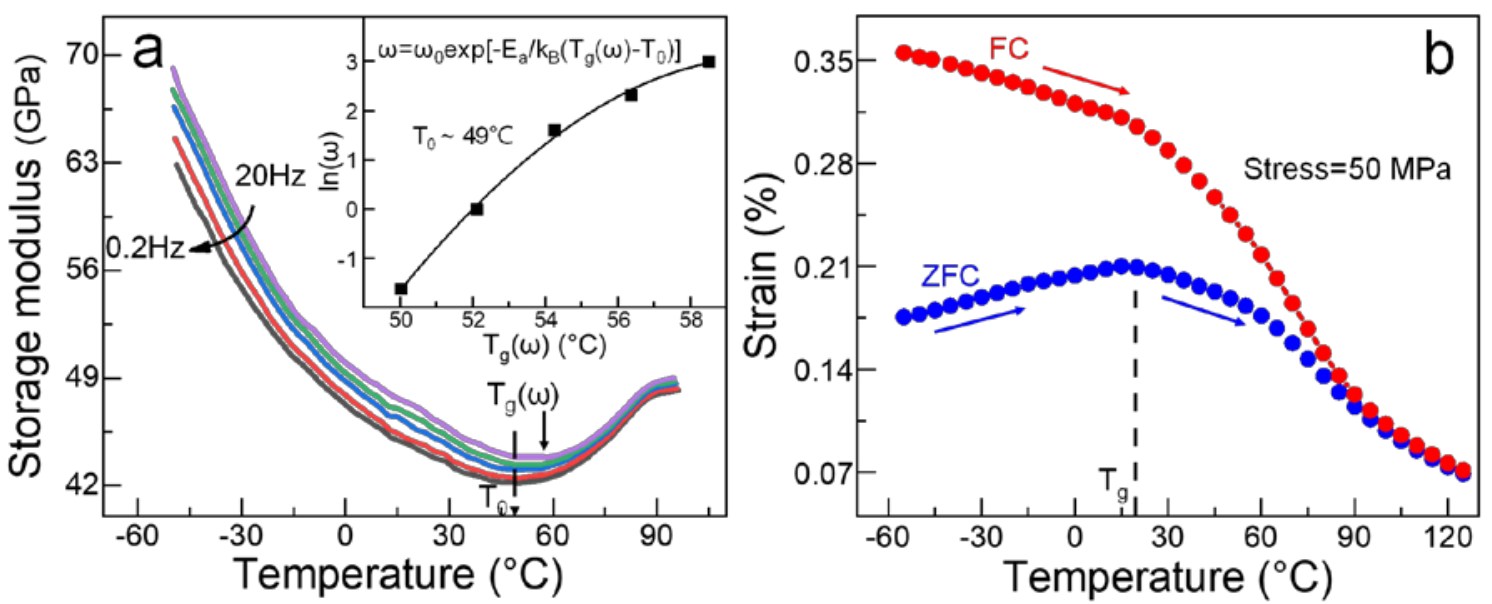

Fig. 3. Dynamic mechanical properties of the nanocrystalline Ti50Ni35 $\mathrm{Pt}_{15}$. (a) Effect of temperature on storage modulus of the nanocrystalline $\mathrm{Ti}_{50} \mathrm{Ni}_{35} \mathrm{Pt}_{15}$ at different frequencies. (b) ZFC/FC curves of the nanocrystalline $\mathrm{Ti}_{50} \mathrm{Ni}_{35} \mathrm{Pt}_{15}$. The sample was cooled to $-150{ }^{\circ} \mathrm{C}$ under zero applied force, denoted zero-field cooling, or ZFC. Then a tensile stress of $50 \mathrm{MPa}$ was applied and the sample was heated to $300{ }^{\circ} \mathrm{C}$ under this stress, presented as the ZFC curve in the figure. Then the sample was cooled to $-150{ }^{\circ} \mathrm{C}$ under the $50 \mathrm{MPa}$ tensile stress, denoted the field cooling, or FC and then heated to $300^{\circ} \mathrm{C}$ again under the same stress, presented as the FC curve in the figure. For each curve, the effect of thermal dilation has been removed by subtracting the strain-temperature curve measured upon the first cooling under zero stress.

\subsection{Mechanical behavior of nanocrystalline strain glass $\mathrm{Ti}_{50} \mathrm{Ni}_{35} \mathbf{P t}_{15}$}

Fig. 4 shows the mechanical behavior of the nanocrystalline $\mathrm{Ti}_{50} \mathrm{Ni}_{35} \mathrm{Pt}_{15}$ alloy. Fig. 4a presents the tensile stress-strain curves at different temperatures. The alloy exhibited an increasing strain hardening between $2 \sim 4 \%$ strain, implying a stress induced transformation. At above $200{ }^{\circ} \mathrm{C}$, the alloy deformed largely via plastic deformation. Fig. 4b plots the apparent Young's modulus and the elongation of the samples tested at different temperatures. It is seen that the alloy exhibited the highest elongation of $11 \%$ at the room temperature, which deteriorated on both heating and cooling. The apparent Young's modulus was $67 \mathrm{GPa}$ at above $300{ }^{\circ} \mathrm{C}$, decreased with decreasing temperature to reach a minimum of $30 \mathrm{GPa}$ at $25 \sim-60{ }^{\circ} \mathrm{C}$, and then increased upon further cooling. The decrease of the elastic modulus implies the participation of nonelastic deformation during this early stage of deformation, e.g. a stress induced phase transformation. Similar observations have also been reported in the literature. Fukuda et al. [29] reported that the apparent Young's modulus of the B2 austenite decreased with decreasing temperature in $\mathrm{Ti}_{50} \mathrm{Ni}_{44} \mathrm{Fe}_{6}$ and attributed the observation to the occurrence of the incommensurate-commensurate transformation in the alloy. Šittner et al. [30] observed a significant decrease of the apparent Young's modulus from 70 GPa to 20 GPa associated with the stress-induced B2-R phase transformation during the apparent linear stage of deformation. 

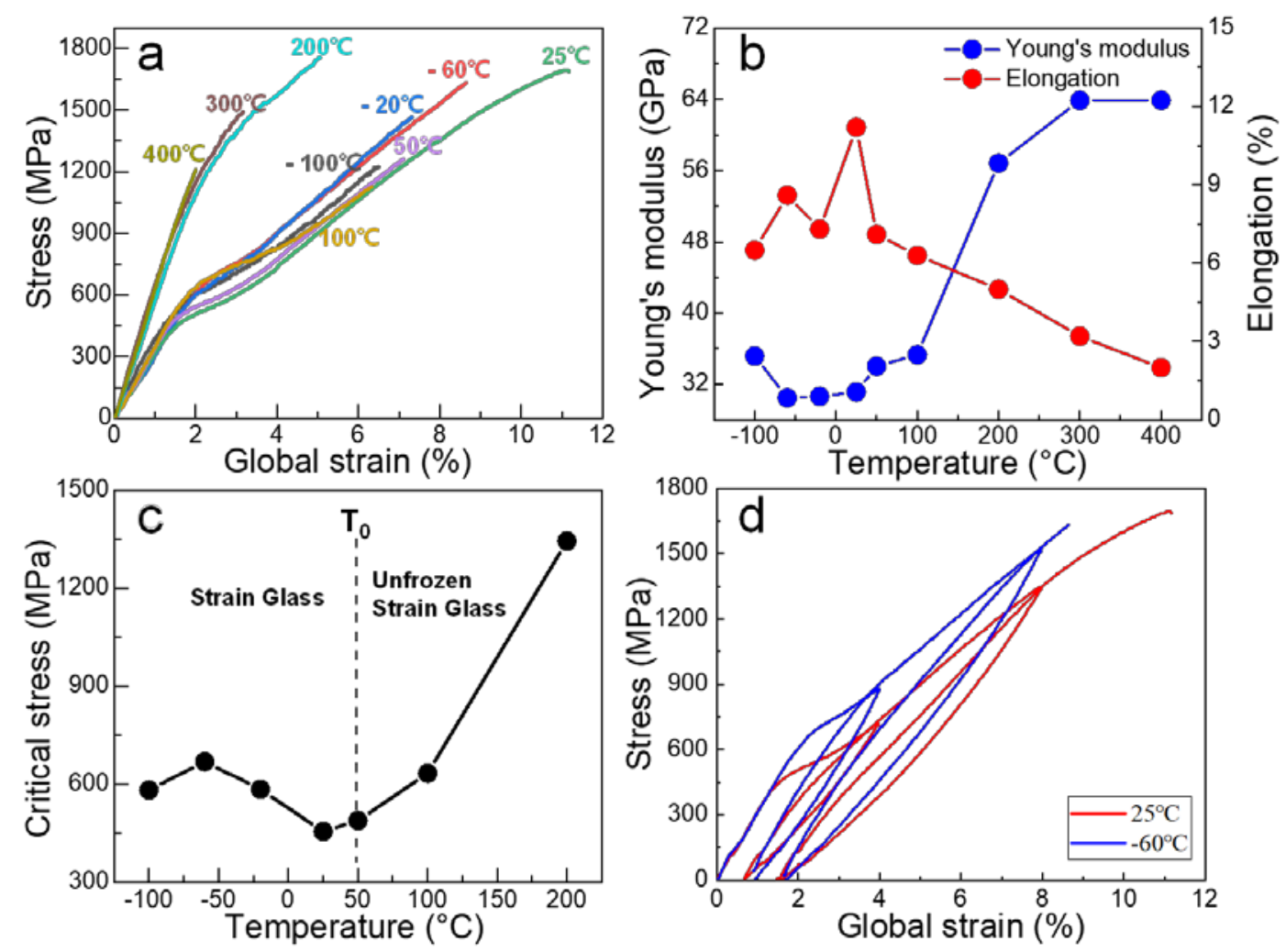

Fig. 4. Mechanical behavior of the nanocrystalline $\mathrm{Ti}_{50} \mathrm{Ni}_{35} \mathrm{Pt}_{15}$ alloy. (a) Tensile stress-strain curves at different temperatures. (b) Effect of testing temperature on the apparent Young's modulus and elongation. (c) Temperature dependence of the critical stress for stress-induced transformation, (d) Progressive deformation curves at the room temperature and $-60{ }^{\circ} \mathrm{C}$.

Fig. 4c shows the effect of temperature on the critical stress for stress-induced martensitic transformation. The critical stress was estimated as the apparent "yielding" point using the conventional tangent method. The critical stress decreased rapidly with decreasing temperature from $100{ }^{\circ} \mathrm{C}$ to $25{ }^{\circ} \mathrm{C}$ and then increased with further decreasing the temperature. This is different from the conventional Clausius-Clapeyron relationship for stress-induced martensitic transformations [31], but similar to that of Ni51.5Ti48.5 and $\mathrm{Ni}_{45} \mathrm{Co}_{5} \mathrm{Mn}_{36} \mathrm{In}_{14}$ alloys [15, 32]. The increase of the critical stress for stress-induced martensitic transformation upon cooling was attributed to an increased stress hysteresis.

Fig. 4d shows the stress-strain curves of two samples tested at two different temperatures, both within the frozen strain glass state range of the alloy. The alloy was superelastic at both the room temperature and $-60^{\circ} \mathrm{C}$. The superelastic strain (recovered strain) reached was $6.35 \%$ at the room temperature and $6.27 \%$ at $-60{ }^{\circ} \mathrm{C}$, after deforming to $8 \%$ strain. It has been reported that coarse-grained TiNi exhibited superelasticity in the unfrozen strain glass state at above $\mathrm{T}_{0}$ and shape memory effect in the frozen strain glass state at below $\mathrm{T}_{0}$ [13]. However, this nanocrystalline $\mathrm{Ti}_{50} \mathrm{Ni}_{35} \mathrm{Pt}_{15}$ alloy is superelastic in the frozen strain glass state at below its $\mathrm{T}_{0}$. This may be related to its small grain sizes. It is also evident that the stress-induced transformation occurred over a progressively over a wide stress window, instead of over a stress plateau. This indicates a complex deformation process. The actual deformation mechanisms 
may include elastic deformation of B2(SG), lattice distortion of the strain glass nanodomains, stress induced $\mathrm{B} 2 \rightarrow \mathrm{R} \rightarrow \mathrm{B} 19$ and $\mathrm{B} 2 \rightarrow \mathrm{B} 19$ transformations, and plastic deformation upon loading, and elastic recovery, pseudoelastic reverse B19 $\rightarrow$ B2(SG) transformation, and lattice distortion recovery of the strain glass nanodomains. The lattice distortion of the stain glass nanodomains is expected to commence at very low stress levels and its participation gives the very low apparent Young's modulus ( 32xxx GPa) of the alloy and the high initial strain ( $1.4 \%)$ before the start of the stress-induced transformation.

Fig. 5 shows an in-situ high-energy synchrotron XRD analysis of the nanocrystalline $\mathrm{Ti}_{50} \mathrm{Ni}_{35} \mathrm{Pt}_{15}$ alloy during two tensile deformation cycles. Stress-strain curves of the sample during in-situ synchrotron XRD test at the room temperature $\left(25^{\circ} \mathrm{C}\right)$ is the same as that presented in Fig. $4 \mathrm{~d}$. The XRD measurement was performed at a step size of $0.2 \%$ strain during the deformation with a stopover time of 10 s to collect the two-dimensional diffraction patterns. Fig. 5a shows 1D XRD patterns for the wire axial direction obtained by integrating the 2D synchrotron XRD within $\pm 5^{\circ}$ about the wire axial direction. In order to make it easier to recognize, the pattern of every $0.4 \%$ strain was used. Some landmark strains are indicated on the side of the figure to deformation stages of the first loading, unloading and the second loading. The diffraction peaks are indexed based on standard crystalline structures of the phases. The lattice parameter of the $\mathrm{B} 2$ phase is $\mathrm{a}=3.015 \AA$. The lattice parameters of the rhombohedral R phase are $a=7.257 \AA, b=7.257 \AA, c=5.383 \AA, \alpha=\beta=90^{\circ}$, and $\gamma=120^{\circ}$. The lattice parameters of the orthogonal B19 phase are $a=2.8000 \AA, b=4.6310 \AA, c=4.1900 \AA, \alpha=\beta=\gamma=90^{\circ}$.

It is worth noting from Fig. 5 a that the (001)R diffraction peak appeared immediately after the tensile deformation (0.4\% strain) prior to the emergence of the (011)B19 diffraction peak and then disappeared gradually upon further loading. This indicates that the sample underwent a stress-induced B2 $\rightarrow \mathrm{R} \rightarrow \mathrm{B} 19$ transformation upon loading. This is similar to the TiNiFe strain glass alloy [27, 33], in which a stress-induced B2(SG) $\rightarrow \mathrm{R}$ transformation was observed. This may explain the reason that the apparent Young's modulus was low at room temperature since the immediate occurrence of the transformation during tensile deformation. During unloading, the B19 $\rightarrow$ B2 transformation was observed, without the reverse B2 $\rightarrow$ R transformation.

Fig. 5b shows an enlarged view of the section of the diffraction pattern between $2.0 \AA$ and 2.4 $\AA$ d-spacing, where (110)в2 and (020)в19 diffractions are visible. The thin lines indicate the positions of the respective diffraction peaks under stress-free conditions. It is seen that upon loading the (110)в2 peak shifted gradually to higher d-spacing values, indicating elastic elongation in the loading direction. At 1.4\% strain, the (110)в2 peak gradually disappeared and the (020)B19 peak emerged, which can also be seen clearly from Fig. 5a, indicating the stressinduced B2 $\rightarrow$ B19 phase transformation. The B19 $\rightarrow$ B2 phase transformation occurred between $3.9 \%$ and $0.7 \%$ strains upon unloading. It is also apparent that the newly formed B2 phase continued to contract in the axial direction upon unloading.

Similarly, Fig. 5c shows an enlarged view of the section between $2.95 \AA$ and $3.35 \AA$ d-spacing, where (100)в2 and (011)в19 diffractions are visible. The thin lines indicate the positions of the respective diffraction peaks under stress-free conditions. It is seen that upon loading the (100)в2 peak shifted gradually to higher d-spacing values, indicating elastic elongation in the loading direction. At $1.4 \%$ strain, the (100)в2 peak gradually disappeared and the (011) $\mathrm{B} 19$ peak 
emerged, indicating the stress-induced $\mathrm{B} 2 \rightarrow \mathrm{B} 19$ phase transformation. The $\mathrm{B} 19 \rightarrow \mathrm{B} 2$ phase transformation occurred between $3.9 \%$ and $0.7 \%$ strains upon unloading.

It seems that the (100)в2 peak changes into the (011)B19 peak continuously, however this does not mean that there exists a continuous martensitic transformation. According to the stressstrain curve shown in Fig. 4d, the stress-induced martensitic transformation occurred in a manner of homogeneity, not an inhomogeneous transformation commonly seen as a stress plateau. This means that the illuminating area by the X-ray spot occurred a homogenous transformation. It can also be seen from Fig. 5b that (110)в2 did not disappear completely when the (020)B19 peak appeared, implying that the B2 and B19 phases coexisted during loading. Another reason for this continuous change of the peak position may be caused by the possible existence of the (111)R which is very close to that of (100)B2 and (011)B19 and make them not easy to be separate.



Fig. 5. In situ XRD analysis of the transformation behavior of the nanocrystalline $\mathrm{Ti}_{50} \mathrm{Ni}_{35} \mathrm{Pt}_{15}$ alloy during tensile deformation. (a) 1-D XRD spectra integrated over $\pm 5^{\circ}$ azimuthal angle of the loading direction from the 2-D XRD patterns measured by synchrotron high energy XRD. (b) and (c) enlarged views of sections of the diffraction patterns identified by the boxes in (a).

\section{Discussion}

\section{1 $\mathrm{T}_{\mathbf{0}}$ temperature of nanocrystalline strain glass $\mathrm{Ti}_{50} \mathrm{Ni}_{35} \mathrm{Pt}_{15}$}

The $T_{0}$ temperature is the temperature of the glass transition $\left(\mathrm{T}_{\mathrm{g}}\right)$ from an unfrozen state to the frozen state of a strain glass matrix at $0 \mathrm{~Hz}$, as determined by extrapolating the $\mathrm{T}_{\mathrm{g}}$ measured at different frequencies. Considering that $\mathrm{M}_{\mathrm{s}}$ is the temperature of the martensitic transformation which has been suppressed, it is obvious that $\mathrm{T}_{0}<\mathrm{M}_{\mathrm{s}}$ for the alloy [34]. The $\mathrm{T}_{0}$ temperature for strain glass transition has been reported to be generally in the range of $-100{ }^{\circ} \mathrm{C} \sim-150{ }^{\circ} \mathrm{C}$ for binary Ni-rich TiNi alloys [8], and close to the room temperature for Cr-doped TiPd high- 
temperature SMAs [4]. The $\mathrm{M}_{\mathrm{s}}$ temperature of the coarse-grained $\mathrm{Ti}_{50} \mathrm{Ni}_{35} \mathrm{Pt} 15$ alloy is measured to be $180{ }^{\circ} \mathrm{C}$, as shown in Fig. 2a. This leads to the higher $\mathrm{T}_{0}$ temperature of $49{ }^{\circ} \mathrm{C}$ in the nanocrystalline $\mathrm{Ti}_{50} \mathrm{Ni}_{35} \mathrm{Pt}_{15}$ strain glass alloy as compared to the usual Ni-rich NiTi alloys.

\subsection{The cause of strain glass state of the nanocrystalline $\mathrm{Ti}_{50} \mathrm{Ni}_{35} \mathrm{Pt}_{15}$ alloy}

It is clear above that the nanocrystalline $\mathrm{Ti}_{50} \mathrm{Ni}_{35} \mathrm{Pt}_{15}$ alloy is in strain glass state. To help identify the main cause of the strain glass state, a comparative experiment was conducted on a nanocrystalline Ni51.5Ti48.5 alloy, which is well known to be in strain glass state in the solid solution state. The nanocrystalline $\mathrm{Ni}_{51.5} \mathrm{Ti}_{48.5}$ alloy was obtained by the same cold wire drawing and low temperature crystallization annealing process as used for the nanocrystalline $\mathrm{Ti}_{50} \mathrm{Ni}_{35} \mathrm{Pt}_{15}$ alloy, except that the crystallization temperature was $370{ }^{\circ} \mathrm{C}$ since its lower crystallization peak temperature.

Fig. 6 shows the thermal analyses of the transformation behavior of a Ni-rich TiNi alloy. Fig. 6a shows a comparison of the electrical resistance - temperature curves of a nanocrystalline $\mathrm{Ni}_{51.5} \mathrm{Ti}_{48.5}$ sample and a coarse-grained sample of the same alloy. The nanocrystalline $\mathrm{Ni}_{51.5} \mathrm{Ti}_{48.5}$ sample showed an obvious B2-R phase transformation at $20-50{ }^{\circ} \mathrm{C}$. In comparison, the coarse-grained sample showed a continuous increase of the electrical resistance with decreasing temperature, a typical behavior of the strain glass transition. Fig. 6b shows the dynamic mechanical behavior of the nanocrystalline Ni51.5Ti48.5 sample, which also manifested the occurrence of the B2-R transformation. It is also evident in the inset that there is no frequency dependence of critical value of the storage modulus, implying that it is associated with the phase transformation and not the strain glass transition. Fig. 6c shows the dynamic mechanical behavior of the coarse-grained $\mathrm{Ni}_{51.5} \mathrm{Ti}_{48.5}$ sample. The critical temperature of the storage modulus exhibited a clear frequency dependence, signaling the strain glass state of the alloy.
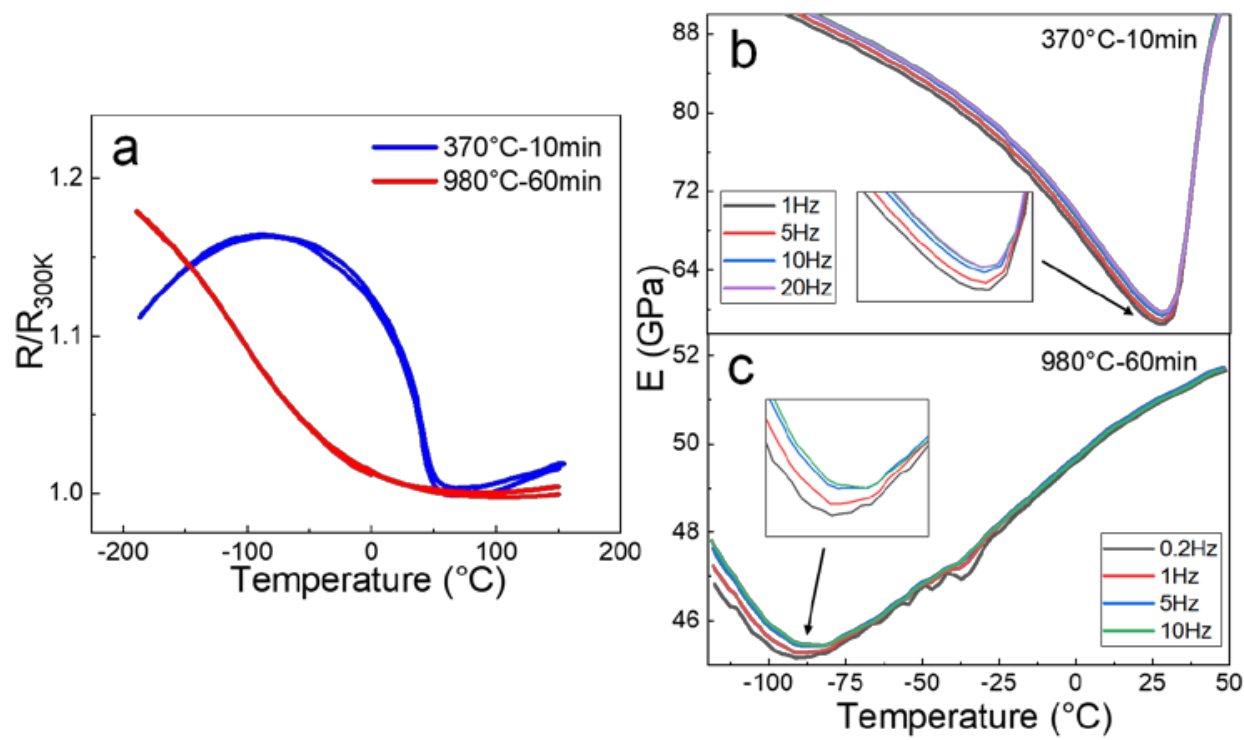

Fig. 6. The transformation behavior of the nanocrystalline and coarse grained Ni51.5Ti48.5 alloys. (a) Normalized electrical resistivity curves of a nanocrystalline sample and a solid solution 


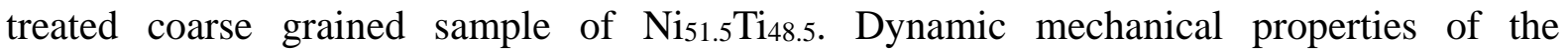
nanocrystalline Ni51.5Ti48.5 (b) and the solid solution treated coarse grained Ni51.5Ti48.5 (c).

In summary, the comparative study demonstrates that the nanocrystalline $\mathrm{Ni}_{51.5} \mathrm{Ti}_{48.5}$ alloy is not in strain glass state but the coarse-grained $\mathrm{Ni}_{51.5} \mathrm{Ti}_{48.5}$ alloy is. In comparison, the nanocrystalline $\mathrm{Ti}_{50} \mathrm{Ni}_{35} \mathrm{Pt}_{15}$ alloy is in strain glass state but the coarse-grained alloy is not. $\mathrm{A}$ possible microscopic origin of the observed macroscopic behavior is explained as follows, and expressed in Fig. 7. In the coarse-grained Ni-rich Ni51.5Ti48.5, the excess $\mathrm{Ni}$ atoms form effectively BCC unit cells within the B2 matrix, as shown in Fig. 7a. Apparently, the presence of these all-Ni BCC unit cells in the matrix disrupts the long range B2 ordering and causes the strain glass state in the coarse-grained $\mathrm{Ni}_{51.5} \mathrm{Ti}_{48.5}$. Given the alloy composition, there are 1.5 Ni-BCC unit cells for every 48.5 TiNi-B2 unit cells, i.e. they count for $3 \%$ of all the unit cells. This leaves an average inter-BCC cell distance of 3.2 unit cells, or about $1 \mathrm{~nm}$. Such B2-BCC configuration is apparently sufficient to suppress the martensitic transformations and causing the strain glass state in the alloy. In a nanocrystalline matrix, on the other hand, the excess Ni atoms are mostly accommodated within the grain boundaries due to their higher solubility for solute atoms, as schematically illustrated in Fig. 7b. This reduces the degree of offstoichiometry for the B2 nano grains, leaving the grain composed of pure TiNi-B2 unit cells, thus the absence of the strain glass state.

For the $\mathrm{Ti}_{50} \mathrm{Ni}_{35} \mathrm{Pt}_{15}$ alloy, the composition is "equiatomic" between $\mathrm{Ti}$ and $(\mathrm{Ni}, \mathrm{Pt})$ for the $\mathrm{B} 2$ structure. Therefore, the matrix can be considered to be composed of two types of B2 unit cells, i.e. TiNi-B2 (B2(Ni)) and TiPt-B2 (B2(Pt)), in 70\% and 30\% proportions, as expressed in Fig. 7c. The absence of a strain glass state in the coarse-grained $\mathrm{Ti}_{50} \mathrm{Ni}_{35} \mathrm{Pt}_{15}$ implies that the $\mathrm{B} 2(\mathrm{Ni})-$ $\mathrm{B} 2(\mathrm{Pt})$ combination is a weak disruption of the B2 ordering and is insufficient to suppress the martensitic transformation. In a nanocrystalline matrix, the "equiatomic" nature implies that there is no grain boundary segregation of any element and the matrix remains in B2(Ni)-B2(Pt) combination. With the additional contribution of the large amount of grain boundaries, the matrix resistance to the martensitic transformation is sufficient to cause the strain glass state, as expressed in Fig. 7d. It is to be stated that, whereas clearly presenting a logical argument, this theory of the original of strain glass is yet to be directly proven, either experimentally by determining the atomic positioning in with the matrix or theoretical calculations by means of density functional theories or molecular dynamics simulation. 


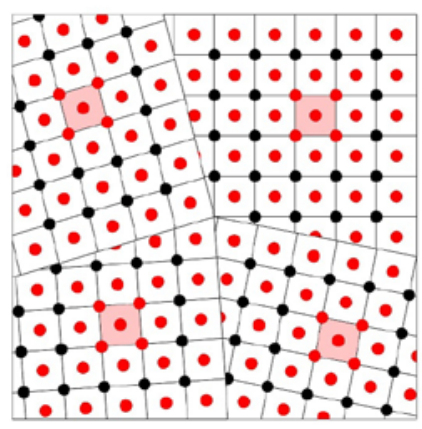

(a) B2(Ni)+BCC

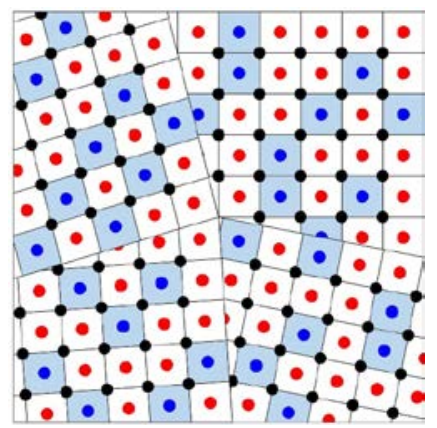

(c) $\mathrm{B} 2(\mathrm{Ni})+\mathrm{B} 2(\mathrm{Pt})$



(b) B2(Ni)

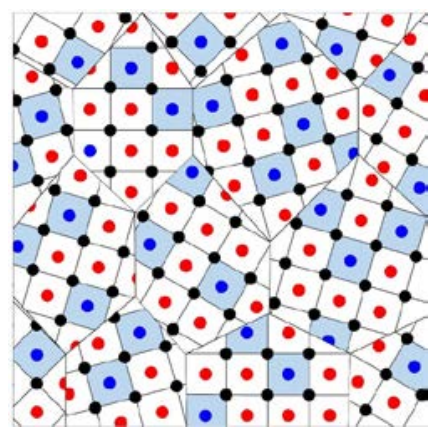

(d) B2(Ni)+B2(Pt)
- Ti atom

- Ni atom

- Pt atom

\section{$\because \quad B C C-N i$}

B2-TiNi

B2-TiPt

Fig. 7. Schematic illustrations of the unit cell configurations in (a) coarse-grained Ni-rich TiNi alloy, (b) nanocrystalline Ni-rich TiNi alloy, (c) coarse-grained $\mathrm{Ti}_{50} \mathrm{Ni}_{35} \mathrm{Pt}_{15}$ alloy, and (d) nanocrystalline $\mathrm{Ti}_{50} \mathrm{Ni}_{35} \mathrm{Pt}_{15}$ alloy.

\section{Conclusions}

The main findings of this study may be summarized as below.

(1). The nanocrystalline $\mathrm{Ti}_{50} \mathrm{Ni}_{35} \mathrm{Pt}_{15}$ alloy is in strain glass state. The $\mathrm{T}_{0}$ temperature of the nanocrystalline strain glass $\mathrm{Ti}_{50} \mathrm{Ni}_{35} \mathrm{Pt}_{15}$ alloy is about $50{ }^{\circ} \mathrm{C}$, which is the highest among all the TiNi-based strain glass alloys to date.

(2). The nanocrystalline strain glass $\mathrm{Ti}_{50} \mathrm{Ni}_{35} \mathrm{Pt}_{15}$ exhibited a B2 $\rightarrow \mathrm{R} \rightarrow \mathrm{B} 19$ superelasticity with a strain recovery exceeding $6 \%$ at room temperature and $-60{ }^{\circ} \mathrm{C}$, a temperature $100{ }^{\circ} \mathrm{C}$ below $\mathrm{T}_{0}$. The nanocrystalline strain glass $\mathrm{Ti}_{50} \mathrm{Ni}_{35} \mathrm{Pt}_{15}$ also exhibited a low apparent Young's modulus of $\sim 30 \mathrm{GPa}$.

(3). The strain glass state in $\mathrm{Ti}_{50} \mathrm{Ni}_{35} \mathrm{Pt}_{15}$ is achieved by the combined effects of Pt substitution for $\mathrm{Ni}$ and nanocrystallinity, neither being sufficient alone. A possible microscopic origin of the formation of strain glass state is that the B2-BCC matrix unit cell configuration in doped non-stoichiometric alloys is more effective in causing the strain glass state than the B2(1)-B2(2) configuration in substitutional stoichiometric alloys.

\section{Acknowledgments}

The authors gratefully acknowledge the financial support of the National Natural Science Foundation of China (Grant Nos. 51731010, 51831006, 51971243), and the financial support of Australian Research Council in grants DP180101955 and DP190102990. This research used resources of the Advanced Photon Source, a U.S. Department of Energy (DOE) Office of Science User Facility operated for the DOE Office of Science by Argonne National Laboratory 
under Contract No. DE-AC02-06CH11357.

\section{References}

[1] C. Liu, Y. Ji, X. Ren, Strain Glass and Novel Properties. Shap. Mem. Superelasticity. 5 (2019) 299-312.

[2] S. Sarkar, X. Ren, K. Otsuka, Evidence for Strain Glass in the Ferroelastic-Martensitic System Ti(50-x)Ni(50+x), Phys. Rev. Lett. 95 (2005) 205702.

[3] Y. Wang, X. Ren, K. Otsuka, A. Saxena, Evidence for broken ergodicity in strain glass, Phys. Rev. B 76 (2007) 132201.

[4] Y. Zhou, D. Xue, X. Ding, K. Otsuka, J. Sun, X. Ren, High temperature strain glass in $\mathrm{Ti}_{50} \mathrm{Pd}_{50-\mathrm{x}} \mathrm{Cr}_{\mathrm{x}}$ alloy and the associated shape memory effect and superelasticity, Appl. Phys. Lett. 95 (2009) 151906.

[5] Y. Wang, Y. Zhou, J. Zhang, X. Ding, S. Yang, X. Song, X. Ren, K. Otsuka, Evolution of the relaxation spectrum during the strain glass transition of Ti48.5Ni51.5 alloy, Acta Mater. 58 (2010) 4723-4729.

[6] Y. Zhou, D. Xue, X. Ding, Y. Wang, J. Zhang, Z. Zhang, D. Wang, K. Otsuka, J. Sun, X. Ren, Strain glass in doped $\mathrm{Ti}_{50} \mathrm{Ni}_{50-\mathrm{x}} \mathrm{D}_{\mathrm{x}}(\mathrm{D}=\mathrm{Co}, \mathrm{Cr}, \mathrm{Mn})$ alloys: Implication for the generality of strain glass in defect-containing ferroelastic systems, Acta Mater. 58 (2010) 5433-5442.

[7] D. Wang, Z. Zhang, J. Zhang, Y. Zhou, Y. Wang, X. Ding, Y. Wang, X. Ren, Strain glass in Fe-doped Ti-Ni, Acta Mater. 58 (2010) 6206-6215.

[8] Z. Zhang, Y. Wang, D. Wang, Y. Zhou, K. Otsuka, X. Ren, Phase diagram of Ti ${ }_{50-x} \mathrm{Ni}_{50+x}$ : Crossover from martensite to strain glass, Phys. Rev. B 81 (2010) 224102.

[9] J. Zhang, D. Xue, X. Cai, X. Ding, X. Ren, J. Sun, Dislocation induced strain glass in Ti50Ni45Fe5 alloy, Acta Mater. 120 (2016) 130-137.

[10] Y. Ji, X. Ding, T. Lookman, K. Otsuka, X. Ren, Heterogeneities and strain glass behavior: Role of nanoscale precipitates in low-temperature-aged Ti48.7Ni51.3 alloys, Phys. Rev. B 87 (2013) 104110.

[11] S. Ren, C. Liu, X. Chen, Y. Hao, X. Ren, Strain glass by aging in Ti-Pd-Fe shape memory alloys, Scripta Mater. 177 (2020) 11-16.

[12] D. Wang, Y. Wang, Z. Zhang, X. Ren, Modeling Abnormal Strain States in Ferroelastic Systems: The Role of Point Defects, Phys. Rev. Lett. 105 (2010) 205702.

[13] Y. Wang, X. Ren, K. Otsuka, Shape Memory Effect and Superelasticity in a Strain Glass Alloy, Phys. Rev. Lett. 97 (2006) 225703.

[14] S. Ren, D. Xue, Y. Ji, X. Liu, S. Yang, X. Ren, Low-field triggered large magnetostriction in iron-palladium strain glass alloys, Phys. Rev. Lett. 119 (2017) 125701.

[15] K. Niitsu, T. Omori, R. Kainuma, Stress-induced transformation behaviors at low temperatures in Ti-51.8Ni (at.\%) shape memory alloy, Appl. Phys. Lett. 102 (2013) 231915.

[16] F.Y. Qin, W.L. Xiao, F.S. Lu, Y.C. Ji, X.Q. Zhao, X.B. Ren, J. Mater. Sci. Technol. 35 (3) (2019) 396-401.

[17] T. Waitz, V. Kazykhanov, H.P. Karnthaler, Martensitic phase transformations in nanocrystalline NiTi studied by TEM, Acta Mater. 52 (2004) 137-147.

[18] X. Shi, L. Cui, D. Jiang, C. Yu, F. Guo, M. Yu, Y. Ren, Y. Liu, Grain size effect on the R- 
phase transformation of nanocrystalline NiTi shape memory alloys, J. Mater. Sci. 49 (2014) 4643-4647.

[19] T. Wang, Z. Ma, X. Rao, D. Jiang, Y. Ren, Y. Liu, K. Yu, L. Cui, Temperature-dependence of superelastic stress in nanocrystalline NiTi with complete transformation capability, Intermetallics. 127 (2020) 106970.

[20] S. Ren, C. Zhou, D. Xue, D. Wang, J. Zhang, X. Ding, K. Otsuka, X. Ren, Sandwich-like strain glass phase diagram of Ti49Ni ${ }_{51-x} P d_{x}$, Phys. Rev. B 94 (2016) 214112.

[21] B. Feng, X. Kong, S. Hao, Y. Liu, Y. Yang, H. Yang, F. Guo, D. Jiang, T. Wang, Y. Ren, L. Cui, In-situ synchrotron high energy X-ray diffraction study of micro-mechanical behaviour of R phase reorientation in nanocrystalline NiTi alloy, Acta Mater. 194 (2020) 565-576.

[22]C. Yu, B. Aoun, L. Cui, Y. Liu, H. Yang, X. Jiang, S. Cai, D. Jiang, Z. Liu, D. E. Brown, Synchrotron high energy X-ray diffraction study of microstructure evolution of severely cold drawn NiTi wire during annealing, Acta Mater. 115 (2016) 35-44.

[23] B. Yao, T. Sun, A. Warren, H. Heinrich, K. Barmak, K.R. Coffey, High contrast hollowcone dark field transmission electron microscopy for nanocrystalline grain size quantification, Micron. 41 (2010) 177-182.

[24] Y. Murakami, D. Shindo, Changes in microstructure near the R-phase transformation in Ti ${ }_{50} \mathrm{Ni}_{48} \mathrm{Fe} 2$ studied by in-situ electron microscopy, Philos. Mag. Lett. 81 (2001) 631-638.

[25] S. Kustov, D. Salas, E. Cesari, R. Santamarta, D. Mari, J.V. Humbeeck, Structural anelasticity, elasticity and broken ergodicity in Ni-Ti shape memory alloys, Acta Mater. 73 (2014) 275-286.

[26] J.C. Qiao, J.M. Pelletier, J. Mater. Sci. Technol., 30 (2014) 523-545

[27] N. Gayathri, A.K. Raychaudhuri, S.K. Tiwary, R. Gundakaram, A. Arulraj, C.N.R. Rao, Electrical transport, magnetism, and magnetoresistance in ferromagnetic oxides with mixed exchange interactions: A study of the La0.7Ca0.3 $\mathrm{Mn}_{1-\mathrm{x}} \mathrm{Co}_{\mathrm{x}} \mathrm{O}_{3}$ system, Phys. Rev. B 56 (1997) 1345-1353.

[28] Q. Tan, J.F. Li, D. Viehland, Role of potassium comodification on domain evolution and electrically induced strains in La modified lead zirconate titanate ferroelectric ceramics, J. Appl. Phys. 88 (2000) 3433-3438.

[29] T. Fukuda, G. Yamasaki, H. Yoshinobu, T. Kakeshita, Mechanical Properties of the RPhase and the Commensurate Phase under [111] Tensile Stress in Iron-Doped TitaniumNickel Alloys, Mater. Trans. 57 (2016) 278-282.

[30] P. Šittner, M. Landa, P. Lukas, V. Novak, R-phase transformation phenomena in thermomechanically loaded NiTi polycrystals, Mech. Mater. 38 (2006) 475-492.

[31] P. Wollants, M. De Bonte, J. Roos, Thermodynamic analysis of the stress-induced martensitic-transformation in a single-crystal, Z. Metallkd. 70 (1979) 113-117.

[32] K. Niitsu, X. Xu, R.Y. Umetsu, R. Kainuma, Stress-induced transformations at low temperatures in a $\mathrm{Ni}_{45} \mathrm{Co}_{5} \mathrm{Mn}_{36} \mathrm{In}_{14}$ metamagnetic shape memory alloy, Appl. Phys. Lett. 103 (2013) 242406.

[33] J. Zhang, Y. Wang, X. Ding, Z. Zhang, Y. Zhou, X. Ren, K. Otsuka, J. Sun, M. Song, Stress-induced strain glass to martensite (R) transition in a Ti50Ni44.5Fe5.5 alloy, Phys. Rev. B 83 (2011) 174204.

[34] Y. Zhou, D. Xue, X. Ding, K. Otsuka, J. Sun, X. Ren, High temperature strain glass 
transition in defect doped Ti-Pd martensitic alloys, Phys. Status Solidi B 251 (2014) 20272033. 